\title{
Air-Assisted Alkanol-Based Nanostructured Supramolecular Liquid-Liquid Microextraction for Extraction and Spectrophotometric Determination of Morin in Fruit and Beverage Samples
}

\author{
Özge Demir ${ }^{1}$ Mustafa Tuzen ${ }^{2,3}$ (1) $\cdot$ Nail Altunay $^{4} \cdot$ Mohammad Reza Afshar Mogaddam $^{5,6}$
}

Received: 24 March 2021 / Accepted: 9 August 2021 / Published online: 1 September 2021

(c) The Author(s), under exclusive licence to Springer Science+Business Media, LLC, part of Springer Nature 2021

\begin{abstract}
A new air-assisted liquid-liquid microextraction method based on alkanol nanostructured supramolecular solvents coupled to spectrometric analysis was developed for extraction, preconcentration, and spectrophotometric determination of morin. $\mathrm{Al}(\mathrm{III})$-morin complex was performed at $\mathrm{pH}$ 4.5. Four different alkanol-based SUPRAS (supramolecular solvents) were prepared for the separation and preconcentration of Al-morin complex from aqueous solution by using vortex and centrifugation. Effect of analytical variables and tolerance limit of matrix ions were investigated. Under the optimum conditions, detection limit, quantification limit, relative standard deviation, preconcentration factor, and enhancement factor were found as $3.5 \mu \mathrm{g} \mathrm{L}^{-1}, 10 \mu \mathrm{g} \mathrm{L}^{-1}, 3.1 \%, 120$, and 95 , respectively. The accuracy of the method was performed with standard addition. The obtained results demonstrated the applicability of the method for the separation, preconcentration, and determination of morin in fruit and beverage samples. The method also complies with green chemistry principles as it uses green solvents, reduces reagent volumes, and produces low amounts of waste.
\end{abstract}

Keywords Air-assisted alkanol-based microextraction · Supramolecular solvent · Liquid-liquid microextraction · Morin · Fruit · Beverage

\section{Introduction}

Flavonoids are polyphenolic compounds that have important health effects such as antioxidant, antiviral, antiallergic, and anti-inflammatory (Hadjmohammadi et al. 2013; Pietta

Mustafa Tuzen

mustafa.tuzen@gop.edu.tr

1 Faculty of Sciences, Department of Chemistry, Sivas Cumhuriyet University, TR-58140 Sivas, Turkey

2 Faculty of Science and Arts, Chemistry Department, Tokat Gaziosmanpasa University, 60250 Tokat, Turkey

3 Research Institute, Center for Environment and Water, King Fahd University of Petroleum and Minerals, Dhahran 31261, Saudi Arabia

4 Faculty of Sciences, Department of Chemistry, Sivas Cumhuriyet University, TR-58140 Sivas, Turkey

5 Food and Drug Safety Research Center, Tabriz University of Medical Science, Tabriz, Iran

6 Pharmaceutical Analysis Research Center, Tabriz University of Medical Science, Tabriz, Iran
2000; Cao et al. 1997; Arancibia et al. 2017). Some plants, vegetables, fruits, beverages, and food samples are rich with respect to flavonoids (Kokulnathan et al. 2018; Jiang et al. 2008). Flavonoids are beneficial for some diseases such as cancer, cardiovascular, diabetes, Alzheimer's, and rheumatoid arthritis (Sani et al. 2020; Chen and Chen 2013; Scalbert et al. 2005). There are many pharmaceutical samples containing flavonoids in the markets. Recent studies have reported that flavonoids have an important role in inhibiting key proteins involved in the coronavirus infection cycle (Russo et al. 2020). It is recommended that flavonoid intake decreases the risk of coronary heart disease and cardiovascular disease (Kim and Je 2017). Estimated daily intake of flavonoids has been reported as $165.6 \mathrm{mg} \mathrm{day}^{-1}$ for Chinese adults ( $\mathrm{Li}$ et al. 2013) and $379.1 \mathrm{mg} \mathrm{day}^{-1}$ for US Adults (Huang et al. 2020). Morin (2-(2,4-dihydroxyphenyl)-3,5,7-trihydroxychromen-4-one) is an important flavonoid and it can interact with nucleic acids, proteins, enzymes, free radicals (Altunay et al. 2019). Morin is widely distributed in vegetables, fruits, and several Chinese herbs. The contents of morin in foodstuffs have been reported in range of $2-250 \mathrm{mg} \mathrm{kg}^{-1}$ in fruits, $3-13 \mathrm{mg} \mathrm{L}^{-1}$ 
in fruit juices, $0-100 \mathrm{mg} \mathrm{kg}^{-1}$ in vegetables, $4-16 \mathrm{mg} \mathrm{L}^{-1}$ in red wine, $10-25 \mathrm{mg} \mathrm{L}^{-1}$ in tea, and $200-600 \mathrm{mg} \mathrm{kg}^{-1}$ in onions, respectively (Hertog et al. 1992, 1993). Considering these properties, it is of great importance to develop a fast and reliable technique for the analysis of this compound in various samples such as biological, food, fruit, and vegetable.

Flavonoids including morin have been determined in different matrix by using analytical techniques such as spectrophotometer (Mayahi and Rajabi 2017), high-performance liquid chromatography (Hadjmohammadi et al. 2013), gas chromatography mass spectrometry (Fiamegos et al. 2004), capillary electrophoresis (Memon et al. 2018), electrooxidation (Ziyatdinova et al. 2014), and diffuse reflectance spectroscopy (Dmitrienko et al. 2012). The spectrophotometer includes some advantages such as efficiency, simplicity, ease of use, and cheapness. Moreover, it is readily available at routine laboratories. Direct determination of morin in fruit and beverage samples by using spectrophotometer is difficult due to the low detection limit of the instrument and the matrix effect. Various separation and preconcentration methods such as hollow fiber liquid-phase microextraction (Hadjmohammadi et al. 2013), ultrasound extraction (Qiao et al. 2011), solid-phase microextraction (Majidi and Hadjmohammadi 2019), ionic liquid dispersive microextraction (Altunay et al. 2019), deep eutectic solvent extraction (Nia and Hadjmohammadi 2019), dispersive magnetic solid-phase extraction (Sani et al. 2020), and air-assisted liquid-liquid microextraction (AA-LLME) (Farajzadeh and Mogaddam 2012) have been reported in the literature for increase the sensitivity of the instrument and decrease the matrix effects.

The AA-LLME technique was first applied in 2012 for the extraction and determination of phthalate esters in aqueous samples (Farajzadeh and Mogaddam 2012). Although this method is basically similar to dispersive liquid-liquid microextraction, no organic solvent is required to disperse an extractant into the sample solution. In this procedure, $\mu \mathrm{L}$ volumes of extraction solvent were dispensed into the sample solution by performing several suction/distribution cycles with the aid of a syringe equipped with a needle. With this procedure, the contact area of the extraction solvent with the sample solution increased significantly even though no dispersing solvent was used (Farajzadeh et al. 2020).

Supramolecular solvents (SUPRAS) are green and cheap for liquid-liquid microextraction (LLME) (Zohrabi et al. 2016). SUPRAS are water-immiscible nanostructured liquids and it provide different interactions such as ionic and hydrogen bonding with organic and inorganic analytes and hydrophobic increase to extraction efficiency (Yilmaz and Soylak 2014; Yang et al. 2017). Alkanolbased supramolecular solvents air-assisted liquid-liquid microextraction (SUPRAS-AA-LLME) method has some advantages such as high efficiency, short extraction time, cost effective, and easy for separation, preconcentration of morin prior to its spectrophotometric determination. According to the literature survey, SUPRAS-AA-LLME method was not used for the separation and preconcentration of morin in fruit and beverage samples.

The main objective of this paper is the development of a new, simple, effective, and green SUPRAS-based AALLME for the extraction and preconcentration of morin in fruit and beverage samples. Application of an alkanolbased SUPRAS (1-dodecanol/THF) in improves the performance of the microextraction procedure reducing the time of analysis, considerably.

\section{Experimental}

\section{Chemicals and Reagents}

Analytical grade chemicals including 1-hexanol ( $\left.\geq 99 \%, d=0.814 \mathrm{~g} \mathrm{~mL}^{-1}\right), 1$-dodecanol $(\geq 98.0 \%$, $\left.d=0.83 \mathrm{~g} \mathrm{~cm}^{-3}\right)$, 1-decanol ( $\left.\geq 99.0 \%, d=0.80 \mathrm{~g} \mathrm{~cm}^{-3}\right)$, 1-tetradecanol ( $\geq 97 \%, d=0.823 \mathrm{~g} \mathrm{~cm}^{-1}$, Sigma), and tetrahydrofuran (Carlo Erba, THF) were used to prepare alkanol-based SUPRASs. Ultrapure water was prepared by Milli-Q water purification system (Millipore, Bedford, MA, USA). Stock solution (1000 $\mathrm{mg} \mathrm{L}^{-1}$ ) of $\mathrm{Al}(\mathrm{III})$ ion was prepared from $\mathrm{Al}\left(\mathrm{NO}_{3}\right)_{3}$ salt (Sigma, St Louis, MO, USA) in water and stored at $4{ }^{\circ} \mathrm{C}$ in a refrigerator. A stock solution of morinhydrate was prepared in ethanol at a concentration of $1000 \mathrm{mg} \mathrm{L}^{-1}$ (Carlo Erba, Milan, Italy) and stored in dark. The calibration solutions were freshly prepared by sequential dilution of the stock solutions. A 5\% $(\mathrm{w} / \mathrm{v})$ of $\mathrm{KCl}$ solution was prepared by dissolving $5.0 \mathrm{~g}$ of $\mathrm{KCl}$ (Sigma) in $100 \mathrm{~mL}$ deionized water. Borate, acetate, phthalate, and citrate buffer solutions were used to adjust solutions $\mathrm{pH}$. To minimize all possible contamination of glassware, a diluted $\mathrm{HNO}_{3}$ solution was used for washing glassware and finally rinsed with distilled water.

\section{Instruments}

A spectrophotometer (Shimadzu 1800 model, Kyoto, Japan) controlled by a HP model computer and equipped with a $500 \mu \mathrm{L}$ quartz cell was used to obtain all analytical measurements. A pH meter (692, Herisau, Switzerland) was used to adjust the $\mathrm{pH}$ of the sample solution. Frequency and temperature-controlled ultrasonic water bath (Kudos, Shanghai, China) was employed in sample preparation and SUPRASs formation. A centrifuge (320R 
model, Universal Hettich, London, UK) was used for phase separation.

\section{Real Samples}

Different fresh fruits and beverage samples, such as kiwi, strawberry, apple, blueberry, orange, pineapple, red wine, cherry juice, apple juice, tangerine juice, herbal tea, and grape fruit juice samples, were obtained from local market in Sivas, Turkey. Since morin is a flavone that can degrade depending on factors such as $\mathrm{pH}$, temperature, and light, ultrasound-assisted sample preparation was applied as follows (Altunay et al. 2019). For degassing of red wine $(10 \mathrm{~mL}), 1.0 \mathrm{~mL} 0.5 \%(\mathrm{v} / \mathrm{v})$ of 1-octanol was added to the sample and vortexed for $2 \mathrm{~min}$. Beverages $(5 \mathrm{~mL})$ and fruit $(3 \mathrm{~g})$ were carefully poured into test tubes and then $2 \mathrm{~mL}$ $0.01 \mathrm{~mol} \mathrm{~L}^{-1}$ of ascorbic acid was added into the mixture in order to ensure the stability of the morin. Following this, $24 \mathrm{~mL}$ of acidic methanol and $6 \mathrm{~mL}$ of $0.2 \mathrm{~mol} \mathrm{~L}^{-1}$ trifluoroacetic acid were added to the resulting mixture, respectively. The test tubes were placed in an ultrasonic bath and sonicated for $15 \mathrm{~min}$ at $40{ }^{\circ} \mathrm{C}$. After centrifugation $(4000 \mathrm{rpm}$ for $5 \mathrm{~min}$ ), the final solution was filtered through a $0.45 \mu \mathrm{m}$ pore size membrane.

\section{Preparation of Alkanol-Based SUPRAS}

Alkanol-based SUPRASs were prepared according to a previously reported method (Moradi et al. 2015). Briefly, 500 $\mu \mathrm{L}$ of each alcohol (1-decanol, 1-hexanol, 1-dodecanol, and 1-tetradecanol) were mixed with $200 \mu \mathrm{L}$ of THF, independently, and the resulting mixture was vortexed for $5 \mathrm{~min}$ at room temperature. After the formation of the alkanol-based SUPRASs, the solution was centrifuged. Subsequently, the less density SUPRASs were removed and used in the next experiments. The composition, mole ratio, and abbreviations of the prepared alkanol-based SUPRAS are given in Table 1.

Table 1 Composition, molar ratio, and abbreviations of the prepared alkanol-based SUPRAS

\begin{tabular}{lllll}
\hline Abbreviations & Composition & & Molar ratio & Recovery (\%) \\
\hline SUPRAS-1 & 1-Decanol & THF & $1: 2$ & 61.7 \\
SUPRAS-2 & 1-Hexanol & THF & $1: 2$ & 81.4 \\
SUPRAS-3 & 1-Dodecanol & THF & $1: 1$ & 85.7 \\
& & & $1: 2$ & 90.1 \\
& & & $1: 3$ & 95.9 \\
& & & $1: 4$ & 84.7 \\
SUPRAS-4 & 1-Tetradecanol & THF & $1: 2$ & 76.2 \\
\hline
\end{tabular}

\section{Alkanol-Based SUPRAS Liquid-Liquid Microextraction}

A $5.0 \mathrm{~mL}$ of the sample solution containing $100 \mu \mathrm{g} \mathrm{L}^{-1}$ of morin was placed into a $15-\mathrm{mL}$ centrifuge tube. Then, 350 $\mu \mathrm{L}$ of $5 \mathrm{mg} \mathrm{L}^{-1} \mathrm{Al}(\mathrm{III})$ solution was added to the sample solution adjusted at $\mathrm{pH} 4.5$. Then, $500 \mu \mathrm{L}$ of 1-dodecanol/ THF SUPRAS (at a molar ratio of 1:3) containing $2.0 \%$ $\mathrm{KCl}(w / v)$ solution was added into the obtained mixture. The resulting mixture was sucked into a $10-\mathrm{mL}$ glass syringe and then injected rapidly through the syringe needle for eight times. After this step, a cloudy mixture, which means the formation of fine droplets of the SUPRAS, was obtained. Then, in order to accelerate the extraction, the centrifuge tubes were placed in an ice bath for $10 \mathrm{~min}$. At this stage, the solidified SUPRAS containing Al-morin complex was collected on the top of the solution and it was carefully transferred to another centrifuge tube, and melted at room temperature. Finally, morin determination was performed by a spectrophotometer at $348 \mathrm{~nm}$ (see Figure S1).

\section{Result and Discussion}

\section{Effect of pH}

In extraction procedures, the analyte molecules could be directed towards the ionization or molecular forms, through $\mathrm{pH}$ adjustment. In order for easier extraction of the analyte from aqueous samples, it must be directed towards neutral forms. In this method, formation of a complex between morin and $\mathrm{Al}(\mathrm{III})$ ions is affected by $\mathrm{pH}$ of the microextraction media. Therefore, the recovery of morin was investigated within the $\mathrm{pH}$ range of 3-9 (see Fig. 1a) by using $300 \mu \mathrm{L}$ of $10^{-3} \mathrm{mmol} \mathrm{L}^{-1}$ of $\mathrm{Al}(\mathrm{III})$ solution, $550 \mu \mathrm{L}$ of SUPRAS mixture of (1:3) molar ratio (1-dodecanol-THF), and $2 \%(\mathrm{w} / \mathrm{v}) \mathrm{KCl}$. Recovery of morin was increased by increasing $\mathrm{pH}$ values and it was reached to quantitative value at $\mathrm{pH} 4.5$ and after $\mathrm{pH} 5.0$ it was decreased. The reason of decrease in recovery of morin at high $\mathrm{pH}$ values may be due to hydrolysis of either $\mathrm{Al}$ (III) with formation of metal hydroxides or decrease in stabilization constant of morin with increasing $\mathrm{pH}$ values. Therefore, the $\mathrm{pH} 4.5$ obtained using the acetate buffer solution was chosen as optimum for the next steps.

\section{Effect of AI(III) Amount}

Chelate formation is an important factor for spectrophotometric determination of morin in SUPRAS-AA-LLME method. The obtained results are given in Fig. 1b. Recovery of morin was found $55 \%$ without $\mathrm{Al}(\mathrm{III})$ ions. When $\mathrm{Al}(\mathrm{III})$ amount increased, recovery of morin was increased and 
(a)

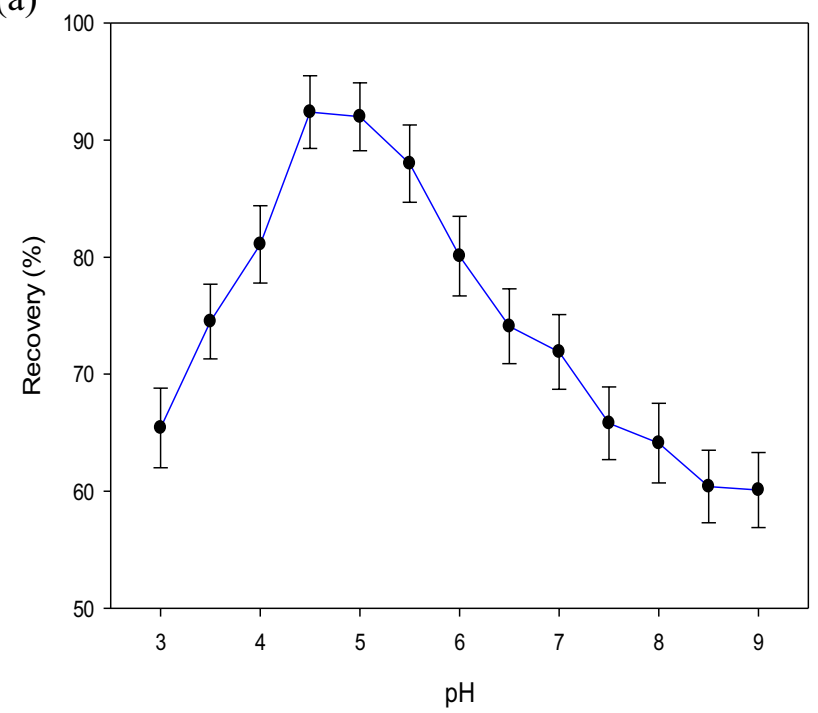

(c)

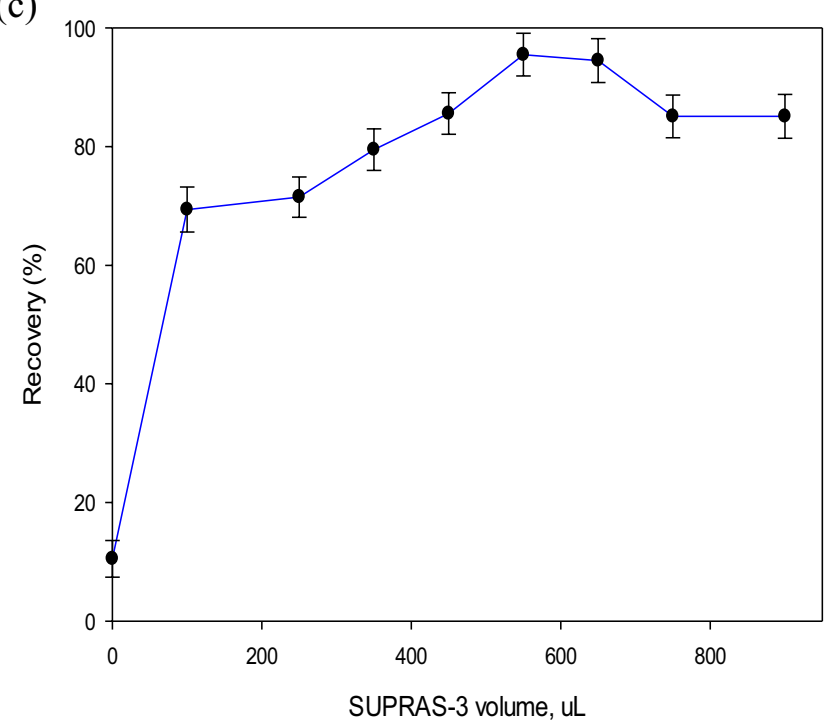

(e)

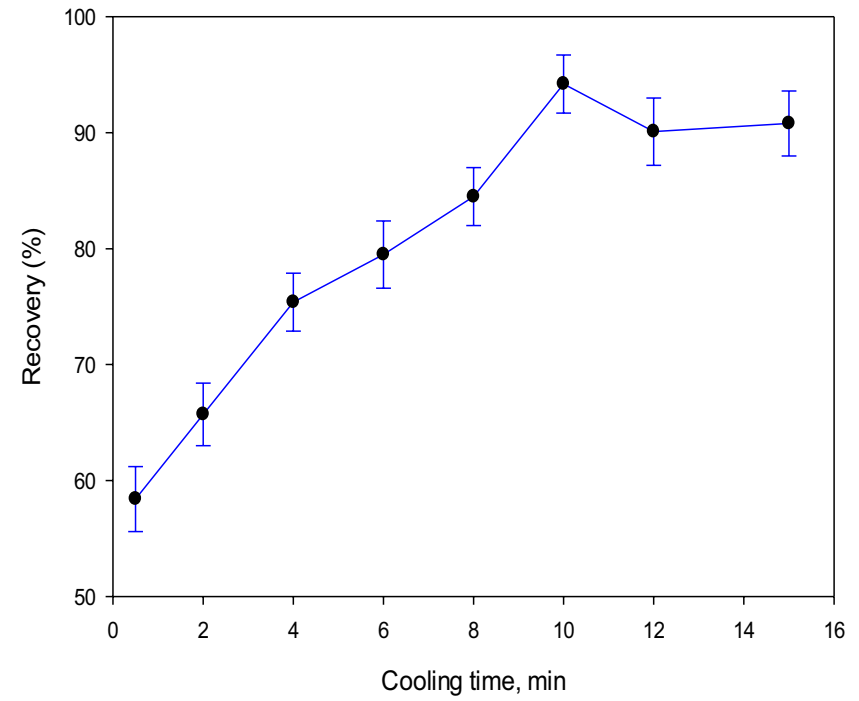

(b)

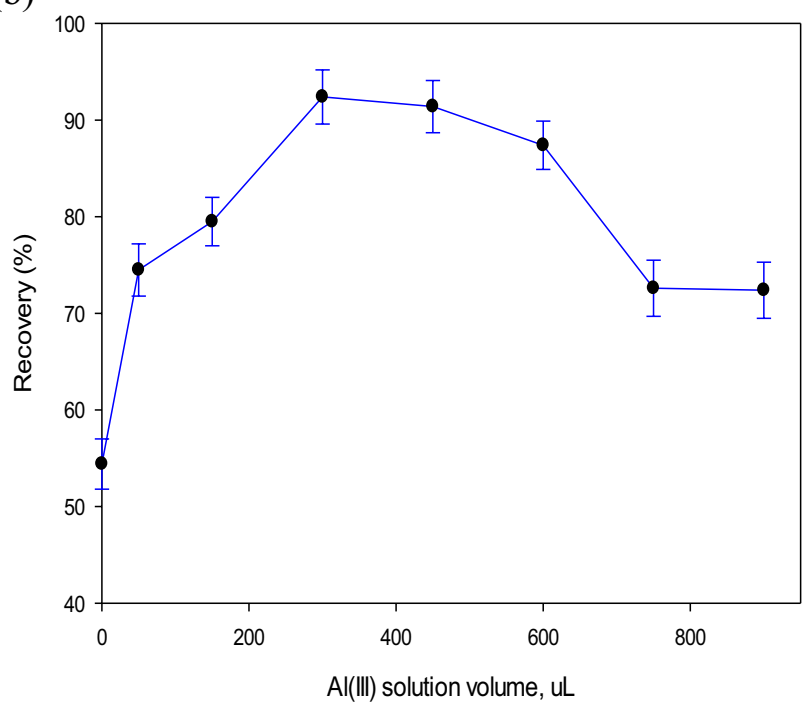

(d)

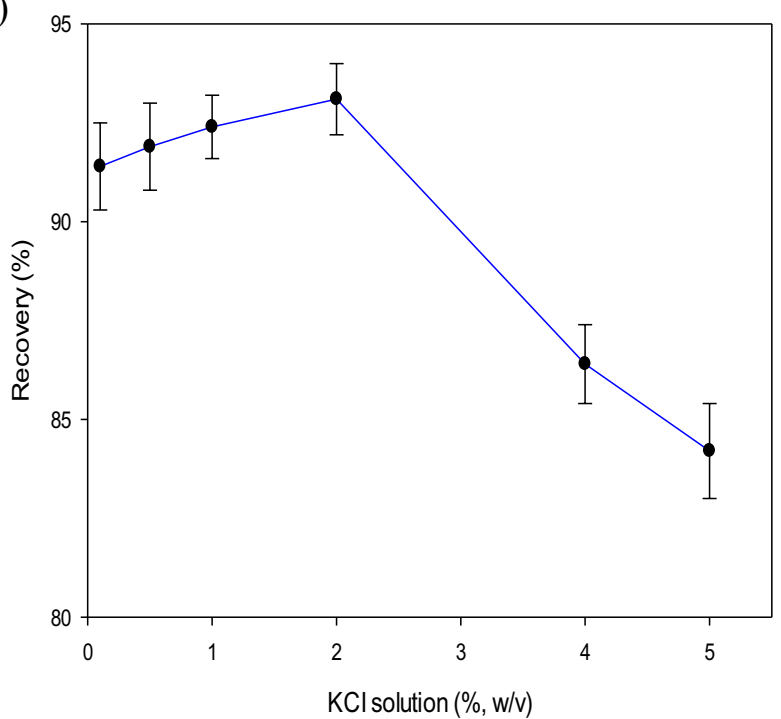

(f)

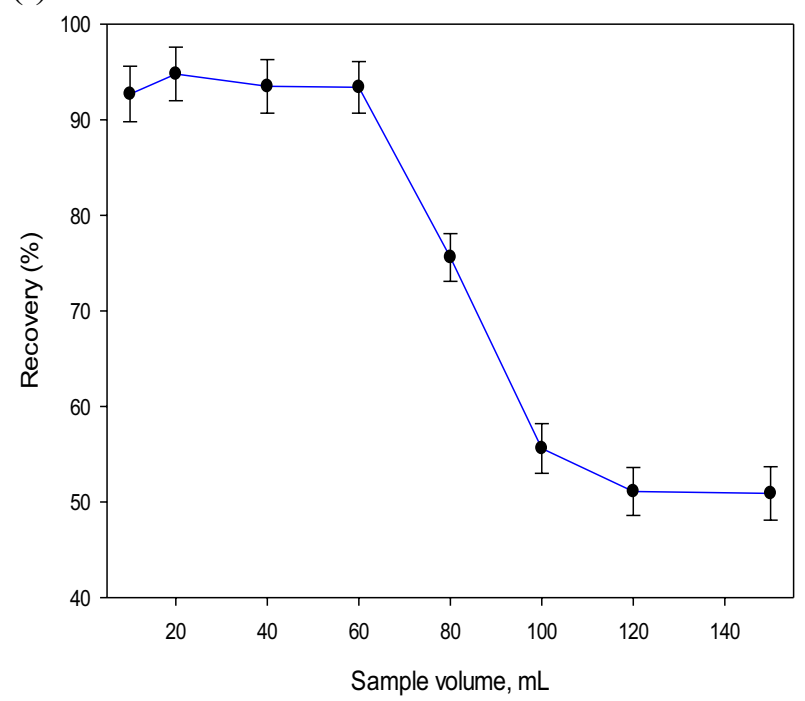


4Fig. 1 a-f The results of the optimization studies. The microextraction conditions were as follows: $5.0 \mathrm{~mL}$ aqueous solution containing morin; $\mathrm{pH}, 4.5 ; 300 \mu \mathrm{L}$ of $10^{-3} \mathrm{mmol} \mathrm{L}^{-1}$ of $\mathrm{Al}(\mathrm{III})$ solution; 550 $\mu \mathrm{L}$ of SUPRAS-3; $2 \%(\mathrm{w} / \mathrm{v}) \mathrm{KCI} ; 10$ min cooling time, and $60 \mathrm{~mL}$ sample volume

reached to quantitative value by using $300 \mu \mathrm{L}$ of $10^{-3} \mathrm{mmol}$ $\mathrm{L}^{-1}$ of $\mathrm{Al}(\mathrm{III})$ solution, $550 \mu \mathrm{L}$ of SUPRAS mixture of (1:3) molar ratio (1-dodecanol-THF), $2 \%$ (w/v) $\mathrm{KCl}$, and 10 min cooling time at $\mathrm{pH} 4.5$. Stable complex formation of morin with $\mathrm{Al}(\mathrm{III})$ ions was increased extraction efficiency of analyte to SUPRAS phase from aqueous solution. When using high amount of Al(III) ions, recoveries were decreased because of increasing reagent blank in sample solution. Therefore, $300 \mu \mathrm{L}$ of $10^{-3} \mathrm{mmol} \mathrm{L}^{-1}$ of $\mathrm{Al}$ (III) solution was chosen as optimum values for $\mathrm{Al}$ (III) solution for the next steps.

\section{Effect of SUPRAS Type and its Composition}

In SUPRAS-AA-LLME method, selection of SUPRAS type and are important factors for both effective phase separation and quantitative analytical results. Alkanol containing SUPRAS provides hydrogen bonding and dispersion interactions for morin in sample solution. Four different alkanolbased SUPRASs were prepared using combinations of THF and 1-decanol, 1-hexanol, 1-dodecanol, and 1-tetradecanol, separately (see Table 1). Quantitative recoveries of morin were found by using SUPRAS-3 (mixture of 1-dodecanol and THF, 1:3 molar ratio) as extraction solvent. Recoveries of morin were found in the range of $61.7-85.7 \%$ by using other alkanol-based SUPRAS composition. The SUPRAS-3 volume was also an important factor for extraction efficiency and formation of microspheres. Therefore, the effect of SUPRAS-3 volume on recovery of morin was investigated in the range of $0.0-900 \mu \mathrm{L}$. Quantitative recoveries of morin were performed by using $550 \mu \mathrm{L}$ SUPRAS-3 (see Fig. 1c). Therefore, $550 \mu \mathrm{L}$ SUPRAS-3 (mixture of 1-dodecanol and THF, 1:3 molar ratio) was chosen as optimum for the next steps.

\section{Effect of lonic Strength}

Due to the fact that ionic salts have the highest solubility in water, addition of them to the solution facilitates the analyte extraction migration into the extraction solvent. Accordingly, easy phase separation and quantitative recovery can be achieved. In order to study the effect of ionic strength on the performance of the present method, different amount of $\mathrm{KCl}$ solutions $(0.1-5 \%)$ was added to model solutions and present method was applied by using $100 \mu \mathrm{g} \mathrm{L}^{-1}$ morin, $300 \mu \mathrm{L}$ of $10^{-3} \mathrm{mmol} \mathrm{L}^{-1}$ of $\mathrm{Al}(\mathrm{III})$ solution, $550 \mu \mathrm{L}$ of SUPRAS mixture of (1:3) molar ratio (1-dodecanol-THF), and $10 \mathrm{~min}$ cooling time at $\mathrm{pH} 4.5$. From the results in Fig. 1d, recoveries of morin were found quantitative until addition of $2 \%$ $\mathrm{KCl}$ solution. When added to $5 \% \mathrm{KCl}$ in sample solution, the recoveries of morin were decreased to $85 \%$ because of causing matrix effects of high amount of salt. Therefore, $2 \% \mathrm{KCl}$ solution was chosen as optimum for the next steps.

\section{Effect of Cooling Time}

The phase containing the analyte and collected on the aqueous solution must be allowed to solidify in order to separate it from the sample solution. If a suitable solidified phase cannot be obtained, phase separation will not be achieved and non-quantitative recovery can be obtained. For these reasons, effect of cooling time on the recovery of morin was investigated in the time ranges from 1 to $15 \mathrm{~min}$. Recovery values were found below $60 \%$ without cooling the sample solution. In order to increase extraction efficiency of analyte, model solution was cooled in ice bath in the range of $1-15$ min using $100 \mu \mathrm{g} \mathrm{L} \mathrm{L}^{-1}$ morin, $300 \mu \mathrm{L}$ of $10^{-3} \mathrm{mmol}$ $\mathrm{L}^{-1}$ of $\mathrm{Al}(\mathrm{III})$ solution, $550 \mu \mathrm{L}$ of SUPRAS mixture of (1:3) molar ratio (1-dodecanol-THF) at $\mathrm{pH} 4.5$ (see Fig. 1e). Model solution was cooled in ice bath for $10 \mathrm{~min}$ to accelerate the extraction of the morin-Al(III) complex into the microspheres. Solidified SUPRAS phase containing Al(III)morin complex was collected on the upper surface of the tubes. The solidified SUPRAS phase was carefully transferred to another test tube and dissolved rapidly at room temperature.

\section{Effect of Sample Volume}

In order to obtain high preconcentration factor (PF), sample volume was a very important factor. PF was calculated by dividing the sample volume to the final collected volume. Different sample solutions in the range of $10-150 \mathrm{~mL}$ containing $50 \mu \mathrm{g} \mathrm{L}^{-1}$ morin were prepared and then subjected to the developed method by using $300 \mu \mathrm{L}$ of $10^{-3} \mathrm{mmol} \mathrm{L}^{-1}$ of $\mathrm{Al}$ (III) solution, $550 \mu \mathrm{L}$ of SUPRAS mixture of $(1: 3)$ molar ratio (1-dodecanol-THF), 10 min cooling time at $\mathrm{pH}$ 4.5 (see Fig. 1e). It was shown that the recoveries of morin were found quantitative till $60 \mathrm{~mL}$ and then decreased at 70-150 mL sample volume. PF, which was calculated as divided of highest sample solution volume $(60 \mathrm{~mL})$ to minimum final solution volume $(0.5 \mathrm{~mL})$, was found 120 .

\section{Matrix Effects}

The tolerance limit of interference ions was defined as ion concentration causes more than $\pm 5 \%$ change in the analytical signal. Levels of interfering ions were very important for the selectivity of the method. Different 
Table 2 The matrix effect on preconcentration and determination of $100 \mu \mathrm{g} \mathrm{L}-1$ morin $(N=3)$

\begin{tabular}{llll}
\hline Interference ions & Tolerance limit & Recovery (\%) & RSD (\%) \\
\hline $\mathrm{Na}(\mathrm{I})$ & 2000 & 98.4 & 2.3 \\
$\mathrm{Ca}(\mathrm{II})$ & 2000 & 97.1 & 2.0 \\
$\mathrm{CO}_{3}$ (II) & 2000 & 98.5 & 2.5 \\
Tartaric acid & 1500 & 98.0 & 2.4 \\
Ascorbic acid & 1500 & 97.8 & 2.3 \\
$\mathrm{SO}_{4}(\mathrm{II})$ & 1500 & 97.5 & 2.1 \\
Nicotinamide & 1500 & 98.6 & 2.0 \\
Apigenin & 1000 & 98.6 & 2.1 \\
Caffeine & 500 & 98.2 & 2.6 \\
Mn(II) & 500 & 97.1 & 2.2 \\
Cu(II) & 500 & 96.4 & 2.3 \\
Citric acid & 250 & 96.2 & 2.1 \\
Zn(II) & 250 & 96.2 & 2.5 \\
Catechin & 250 & 95.7 & 2.4 \\
Fe(III) & 250 & 95.8 & 2.3 \\
Caffeine & 100 & 95.5 & 2.3 \\
Rutin & 100 & 95.3 & 2.4 \\
Quercetin & 100 & 95.1 & 2.2 \\
Kaempferol & 100 & 95.4 & 2.1 \\
\hline
\end{tabular}

levels of possible interfering ions were added to the model solutions containing $100 \mu \mathrm{g} \mathrm{L}^{-1}$ morin and then the presented method was applied. As can be seen from the results in Table 2, there is no significant effect of interference ions on the recovery of morin under the optimized experimental conditions $(300 \mu \mathrm{L}$ of $10^{-3} \mathrm{mmol} \mathrm{L}^{-1}$ of $\mathrm{Al}(\mathrm{III})$ solution, $550 \mu \mathrm{L}$ of SUPRAS mixture of (1:3) molar ratio (1-dodecanol-THF), $10 \mathrm{~min}$ cooling time, and $\mathrm{pH} 4.5$ by using acetate buffer solution). It can be said that SUPRAS-AA-LLME method has high selectivity, and tolerance limit, quantitative recovery (95.1-98.6\%), and low relative standard deviation (RSD) values $(2.1-2.6 \%)$.

\section{Analytical Figure of Merits}

Detection limit (LOD) and quantification limit (LOQ) for the SUPRAS-AA-LLME method were calculated from the equations of $3 \mathrm{~s} / \mathrm{m}$ and $10 \mathrm{~s} / \mathrm{m}$, where $s$ is standard deviation of the eleven-reagent blank solution and $m$ is slope of the calibration curve. LOD and LOQ were found at 3.5 and $10 \mu \mathrm{g} \mathrm{L}^{-1}$ for water samples, 4.1 and $14 \mu \mathrm{g} \mathrm{kg}^{-1}$ for solid samples, respectively. RSD of the present method was found to be $3.1 \%$ from the analysis of ten replicates of $10 \mathrm{~mL}$ sample solution containing $100 \mu \mathrm{g} \mathrm{L}^{-1}$ morin. The linearity was achieved in the range of $10-800 \mu \mathrm{g} \mathrm{L}^{-1}\left(r^{2}=0.9982\right)$, with a linear calibration equation $A=1.34 \times 10^{-3}$ [morin,
Table 3 Analytical features of the present method

\begin{tabular}{ll}
\hline Parameters & Values obtained \\
\hline Calibration equation & $\mathrm{A}=1.34 \times 10^{-3}$ \\
& {$[\mathrm{morin}, \mu \mathrm{g}$} \\
& $\left.\mathrm{L}^{-1}\right]+5.07 \times 10^{-4}$ \\
Regression coefficient $\left(r^{2}\right)$ & 0.9982 \\
Linear range $\left(\mu \mathrm{g} \mathrm{L}^{-1}\right)$ & $10-800$ \\
$\mathrm{LOD}\left(3 \times S_{\text {blank }} / m, \mu \mathrm{g} \mathrm{L}^{-1}\right)$ & 3.5 \\
$\mathrm{LOQ}\left(10 \times S_{\text {blank }} / m, \mu \mathrm{g} \mathrm{L}^{-1}\right)$ & 10 \\
$\mathrm{RSD} \%\left(n: 10,50 \mu \mathrm{g} \mathrm{L}^{-1}\right)$ & 3.1 \\
Preconcentration factor & 120 \\
Enhancement factor & 95 \\
Measurement wavelength, $\mathrm{nm}$ & 348 \\
\hline
\end{tabular}

$\left.\mu \mathrm{g} \mathrm{L}^{-1}\right]+5.07 \times 10^{-4}$ after the developed method. The enhancement factor (EF), calculated from the slope ratio of the calibration graph with and without the SUPRASAA-LLME, was found to be 95 . Comprehensive data are given in Table 3.

\section{Validation and Applications of the SUPRAS-AA-LLME Method}

Precision and accuracy of the method were examined for real sample solutions. The precision of the present method was investigated as RSD and it was found separately for repeatability ( $n: 3$ in the same day) and reproducibility ( $n: 3 \times 3$ in three consecutive days). For the quality control, kiwi and apple juice were used as reference for fruit and beverage samples. The data of the study are given in Table 4 . The RSD values were found lower than $4 \%$ which confirms the acceptable precision of the method. Accuracy of the method was confirmed with standard addition. In the spiked levels of $10-50 \mu \mathrm{g} \mathrm{kg}^{-1}$ for fruit samples and 100-200 $\mu \mathrm{g} \mathrm{L}^{-1}$ for beverage samples, recovery values were found quantitative (95-102\%) and RSD values were found lower than $3 \%$. Overall, the results achieved in the recovery and precision confirm that the method has concentrated and purified the desired analyte from the complex matrix of the selected sample with high accuracy and precision and confirms the validity of the method. Comprehensive data are given in Table 5.

The SUPRAS-AA-LLME method was applied on fruit and beverage samples including kiwi, strawberry, apple, blueberry, orange, pineapple, red wine, cherry juice, apple juice, tangerine juice, herbal tea, and grape fruit juice samples. The data obtained are given in Table 5. All sample solutions were diluted 100-fold in order to decline the morin concentration in the linear working area. The obtained results for morin in analyzed fruit and beverage samples were acceptable for the human consumption. Analyzed samples can make a significant contribution to morin intake. 
Table 4 The accuracy and precision of the present method for two quality control samples after spiking

Table 5 The analysis results of extraction of morin in fruit and beverage samples by using the present method $(n: 5)$

\begin{tabular}{|c|c|c|c|c|c|c|c|}
\hline \multirow[t]{2}{*}{ Samples } & \multirow{2}{*}{$\begin{array}{l}\text { Spiking ( } \mu \mathrm{g} \\
\left.\mathrm{L}^{-1}\right)\end{array}$} & \multicolumn{3}{|c|}{ Intra-day ( $n: 3$ in same day) } & \multicolumn{3}{|c|}{ Inter-day ( $n: 3 \times 3$ in three consecutive days) } \\
\hline & & $\begin{array}{l}\text { Found } \\
\left(\mu \mathrm{g} \mathrm{L}^{-1}\right)\end{array}$ & $\begin{array}{l}\text { RSD } \\
(\%)\end{array}$ & Recovery (\%) & $\begin{array}{l}\text { Found } \\
\left(\mu \mathrm{g} \mathrm{L}^{-1}\right)\end{array}$ & $\begin{array}{l}\text { RSD } \\
(\%)\end{array}$ & Recovery (\%) \\
\hline \multirow[t]{3}{*}{ Kiwi } & 25 & 24.1 & 3.1 & 96.4 & 23.4 & 3.9 & 93.6 \\
\hline & 300 & 305.8 & 2.9 & 101.9 & 307.9 & 3.5 & 102.6 \\
\hline & 600 & 586.1 & 2.7 & 97.7 & 571.8 & 3.1 & 95.3 \\
\hline \multirow[t]{3}{*}{ Apple juice } & 25 & 26.3 & 3.6 & 105.2 & 23.9 & 4.2 & 95.6 \\
\hline & 300 & 288.5 & 3.3 & 96.2 & 282.4 & 3.7 & 94.1 \\
\hline & 600 & 612.4 & 3.0 & 102.1 & 624.5 & 3.4 & 104.1 \\
\hline
\end{tabular}

\begin{tabular}{|c|c|c|c|c|}
\hline Matrix type & Spiked & Found & RSD (\%) & Recovery (\%) \\
\hline \multicolumn{5}{|l|}{ Fruit samples $\left(\mu \mathrm{g} \mathrm{kg}^{-1}\right)$} \\
\hline \multirow[t]{3}{*}{ Kiwi } & - & 81.4 & 2.1 & - \\
\hline & 10 & 91.0 & 2.3 & 96.0 \\
\hline & 50 & 130.2 & 2.4 & 97.5 \\
\hline \multirow[t]{3}{*}{ Strawberry } & - & 179.2 & 2.6 & - \\
\hline & 10 & 188.9 & 2.8 & 97.0 \\
\hline & 50 & 227.8 & 2.8 & 97.2 \\
\hline \multirow[t]{3}{*}{ Apple } & - & 231.8 & 2.0 & - \\
\hline & 10 & 241.3 & 2.4 & 95.0 \\
\hline & 50 & 280.2 & 2.5 & 96.8 \\
\hline \multirow[t]{3}{*}{ Blueberry } & - & 192.1 & 2.2 & - \\
\hline & 10 & 201.8 & 2.5 & 97.0 \\
\hline & 50 & 241.5 & 2.6 & 98.7 \\
\hline \multirow[t]{3}{*}{ Orange } & - & 262.7 & 1.9 & - \\
\hline & 10 & 272.2 & 2.2 & 95.0 \\
\hline & 50 & 311.4 & 2.4 & 97.4 \\
\hline \multirow[t]{3}{*}{ Pineapple } & - & 114.3 & 2.2 & - \\
\hline & 10 & 124.5 & 2.3 & 102.0 \\
\hline & 50 & 165.1 & 2.6 & 101.5 \\
\hline \multicolumn{5}{|l|}{ Beverage samples $\left(\mu \mathrm{g} \mathrm{L}^{-1}\right)$} \\
\hline \multirow[t]{3}{*}{ Red wine (sample 1) } & - & 125.4 & 2.4 & - \\
\hline & 100 & 221.1 & 2.5 & 95.7 \\
\hline & 200 & 321.0 & 2.7 & 97.8 \\
\hline \multirow[t]{3}{*}{ Red wine (sample 2) } & - & 110.2 & 2.5 & - \\
\hline & 100 & 213.7 & 2.6 & 103.5 \\
\hline & 200 & 314.4 & 2.8 & 102.1 \\
\hline \multirow[t]{3}{*}{ Cherry juice } & - & 75.6 & 2.1 & - \\
\hline & 100 & 172.5 & 2.3 & 96.9 \\
\hline & 200 & 270.4 & 2.4 & 97.4 \\
\hline \multirow[t]{3}{*}{ Apple juice } & - & 157.9 & 2.3 & - \\
\hline & 100 & 260.6 & 2.5 & 102.7 \\
\hline & 200 & 361.1 & 2.7 & 101.6 \\
\hline \multirow[t]{3}{*}{ Tangerine juice } & - & 95.1 & 2.7 & - \\
\hline & 100 & 192.5 & 2.8 & 97.4 \\
\hline & 200 & 291.7 & 3.1 & 98.3 \\
\hline \multirow[t]{3}{*}{ Herbal tea } & - & 146.8 & 2.8 & - \\
\hline & 100 & 244.0 & 3.0 & 97.2 \\
\hline & 200 & 344.0 & 3.2 & 98.6 \\
\hline \multirow[t]{3}{*}{ Grapefruit juice } & - & 101.6 & 2.5 & - \\
\hline & 100 & 204.9 & 2.7 & 103.3 \\
\hline & 200 & 305.4 & 2.8 & 101.9 \\
\hline
\end{tabular}


Table 6 Comparison of the present method with previously reported methods in the literature

\begin{tabular}{|c|c|c|c|c|c|c|c|}
\hline $\begin{array}{l}\text { Microextraction } \\
\text { procedure }\end{array}$ & Detection technique & Matrix type & a,b,c Linear range & ${ }^{a, b, c}$ LOD & $\operatorname{RSD}(\%)$ & EF or PF & Refs \\
\hline SBME-DES & HPLC-UV & $\begin{array}{l}\text { Vegetable and fruit } \\
\text { juice }\end{array}$ & a $1-500$ & a 2.6 & 3.5 & 36.1 & $\begin{array}{l}\text { Nia and } \\
\text { Hadjmohammadi } \\
\text { (2019) }\end{array}$ \\
\hline HF-LPME & HPLC-UV & Fruit juice & ${ }^{\mathrm{a}} 5-500$ & ${ }^{\mathrm{a}} 1.5$ & 7.2 & 293 & $\begin{array}{l}\text { Hadjmohammadi } \\
\text { et al. (2013) }\end{array}$ \\
\hline VA-ILME & UV-VIS & Food and beverages & ${ }^{\mathrm{a}} 17.5-450$ & a 5.3 & 1.9 & 50 & Altunay et al. (2019) \\
\hline S-SIL-MSPD & HPLC-DAD & Raw propolis samples & ${ }^{c} 0.09-47.26$ & ${ }^{\mathrm{c}} 0.02$ & $<8.95$ & - & Wang et al. (2014) \\
\hline- & SWV & Grape wine & ${ }^{\mathrm{b}} 0.01-5$ & b 0.0033 & 1.69 & - & Yola et al. (2014) \\
\hline DM-SPE & HPLC-UV & $\begin{array}{l}\text { Fruit juices and veg- } \\
\text { etable }\end{array}$ & a $2.7-500$ & ${ }^{\mathrm{a}} 0.83$ & 3.66 & - & Sani et al. (2020) \\
\hline DES-MD-SPE & HPLC-UV & $\begin{array}{l}\text { Apple and grape } \\
\text { juices, tea }\end{array}$ & a $3-500$ & 0.91 & 3.8 & 39.1 & $\begin{array}{l}\text { Majidi and } \\
\text { Hadjmohammadi } \\
\text { (2019) }\end{array}$ \\
\hline SUPRAS-AA-LLME & UV-VIS & Fruit and beverage & ${ }^{\mathrm{a}} 10-800$ & a 3.5 & 3.1 & 120 & Current study \\
\hline
\end{tabular}

${ }^{\mathrm{a}} \mu \mathrm{g} \mathrm{L}{ }^{-1},{ }^{\mathrm{b}} \mu \mathrm{mol} \mathrm{L}{ }^{-1},{ }^{\mathrm{c}} \mathrm{mg} \mathrm{L} \mathrm{L}^{-1}$

$S B M E-D E S$, solvent bar microextraction based on a deep eutectic solvent; $H P L C-U V$, high-performance liquid-chromatography ultraviolet detection; HF-LPME, hollow fiber liquid-phase microextraction; VA-ILME, vortex-assisted ionic liquid-based microextraction; S-SIL-MSPD, silica-supported ionic liquid-matrix solid-phase dispersion; $S W V$, square wave voltammetry; DM-SPE, dispersive magnetic solid-phase extraction; $D E S-M D$-SPE, alcohol-based deep eutectic based on magnetic dispersive solid-phase extraction

\section{Conclusions}

Simple, rapid, effective, and green SUPRAS-based AA-LLME method was developed for separation, preconcentration, and spectrophotometric determination of morin in fruit and beverage samples. Four different alkanol-based SUPRASs were prepared for the extraction of $\mathrm{Al}(\mathrm{III})$-morin complex from aqueous solution. The accuracy of the present method was confirmed with standard addition method. RSD values were calculated for intra- and inter-day precision and they were found below $4 \%$. The present method has some advantages such as sensitivity, selectivity, and high tolerance limit, short extraction time, low cost, and easy for separation and preconcentration of morin. The comparisons of the SUPRAS-AA-LLME method with literature values are given in Table 6 . In comparison to the other methods, the SUPRAS-AA-LLME method has the advantages of shorter extraction time, simplicity, and applicability in routine analysis laboratories. Moreover, low detection, low RSD, high PF/EF, and wide linear working area were observed in the present method according to literature values. Very complex fruit, beverage, and food samples can be analyzed with the present SUPRAS-AA-LLME method at $\mu \mathrm{g} \mathrm{L}^{-1}$ levels with respect to morin-containing flavonoid samples.

Supplementary Information The online version contains supplementary material available at https://doi.org/10.1007/s12161-021-02111-3.

\section{Declarations}

Ethical Approval This article does not contain any studies with human or animal subjects. This article has not been published before and it is not under consideration for publication anywhere else.

Informed Consent Not applicable.

Conflict of Interest Ozge Demir declares that she has no conflict of interest. Mustafa Tuzen declares that he has no conflict of interest. Nail Altunay declares that he has no conflict of interest. Mohammad Reza Afshar Mogaddam declares that he has no conflict of interest.

\section{References}

Altunay N, Elik A, Gurkan R (2019) A simple and green microextraction procedure for extraction of morin in food and beverages using ionic liquid. Food Anal Methods 12(8):1747-1758

Arancibia V, Beltran OG, Hurtado J, Nagles E (2017) Adsorptive stripping voltammetric determination of morin in tea infusions and chocolate drinks on a gold electrode. Effect of cetylpyridinium bromide on the sensitivity of the method. Int J Electrochem Sci 12:9408-9417

Cao G, Sofic E, Prior RL (1997) Antioxidant and prooxidant behavior of flavonoids: structure-activity relationships. Free Radic Biol Med 22:749-760

Chen AY, Chen YC (2013) A review of the dietary flavonoid, kaempferol on human health and cancer chemoprevention. Food Chem 138:2099-2107

Dmitrienko SG, Apyari VV, Kudrinskaya VA, Stepanova AV (2012) Preconcentration of flavonoids on polyurethane foam and their direct determination by diffuse reflectance spectroscopy. Talanta 102:132-136 
Farajzadeh MA, Mogaddam MRA (2012) Air-assisted liquid-liquid microextraction method as a novel microextraction technique; Application in extraction and preconcentration of phthalate esters in aqueous sample followed by gas chromatographyflame ionization detection. Anal Chim Acta 728:31-38

Farajzadeh MA, Mohebbi A, Pazhohan A, Nemati M, Mogaddam MRA (2020) Air-assisted liquid-liquid microextraction; principles and applications with analytical instruments. TrAC Trends Anal Chem 122:115734

Fiamegos YC, Nanos CG, Vervoort J, Stalikas CD (2004) Analytical procedure for the in-viral derivatization-extraction of phenolic acids and flavonoids in methanolic and aqueous plant extracts followed by gas chromarography with mass-selective detection. J Chromatogr A 1041:11-18

Hadjmohammadi M, Karimiyan H, Sharif V (2013) Hollow fibrebased liquid phase microextraction combined with high-performance liquid chromatography for the analysis of flavonoids in Echinophora platyloba DC. and Mentha piperita. Food Chem 141:731-735

Hertog MGL, Hollman PCH, Katan MB (1992) Content of potentially anticarcinogenic flavonoids of 28 vegetables and 9 fruits commonly consumed in the Netherlands. J Agric Food Chem 40:2379

Hertog MGL, Hollman PCH, van de Putte B (1993) Content of potentially anticarcinogenic flavonoids of tea infusions, wines, and fruitjuices. J Agric Food Chem 41:1242

Huang Q, Braffett BH, Simmens SJ, Young HA, Ogden CL (2020) Dietary polyphenol intake in US adults and 10-year trends: 20072016. J Acad Nutr Diet 120:1821-1833

Jiang L, Fang G, Zhang Y, Cao G, Wang S (2008) Analysis of flavonoids in propolis and Ginkgo biloba by micellar electrokinetic capillary chromatography. J Agric Food Chem 56:11571-11577

Kim Y, Je Y (2017) Flavonoid intake and mortality from cardiovascular disease and all causes: a meta-analysis of prospective cohort studies. Clin Nutr ESPEN 20:68-77

Kokulnathan T, Sakthinathan S, Chen SM, Karthik R, Chiu, \& T.W. (2018) Hexammine cobalt (III) coordination complex grafted reduced graphene oxide composite for sensitive and selective electrochemical determination of morin in fruit samples. Inorg Chem Front 5(5):1145-1155

Li G, Zhu Y, Zhang Y, Lang J, Chen Y, Ling W (2013) Estimated daily flavonoid and stilbene intake from fruits, vegetables, and nuts and associations with lipid profiles in Chinese Adults. J Acad Nutr Diet 113:786-794

Majidi SM, Hadjmohammadi MR (2019) Alcohol-based deep eutectic solvent as a carrier of $\mathrm{SiO}_{2} @ \mathrm{Fe}_{3} \mathrm{O}_{4}$ for the development of magnetic dispersive micro-solid-phase extraction method: application for the preconcentration and determination of morin in apple and grape juices, diluted and acidic extract of dried onion and green tea infusion samples. J Sep Sci 42(17):2842-2850

Mayahi J, Rajabi HR (2017) Comparison study on separation of morin: ultrasound assisted molecularly imprinted polymeric nanoparticles solid phase extraction versus solidification of floating organic-drop assisted dispersive liquid-liquid microextraction. New J Chem 41(23):14236-14245

Memon AF, Solangi AR, Memon SQ, Mallah A, Memon N (2018) Quantitative separation of hesperidin, chrysin, epicatechin, epigallocatechin gallate, and morin using ionic liquid as a buffer additive in capillary electrophoresis. Electrophoresis 39(13):1606-1612

Moradi M, Ferdowsi M, Tqian-Nasab A, Najafi A (2015) Microextraction of methyl and ethyl centralites using an alkanol-based nanostructured solvent followed by high-performance liquid chromatography. J Iran Chem Soc 12(9):1595-1601

Nia NN, Hadjmohammadi MR (2019) The application of three-phase solvent bar microextraction based on a deep eutectic solvent coupled with high-performance liquid chromatography for the determination of flavonoids from vegetable and fruit juice samples. Anal Methods 11(40):5134-5141

Pietta PG (2000) Flavonoids as antioxidants. J Nat Prod 63:1035-1042

Qiao S, Shi R, Liu M, Zhang C, Yang W, Shi X, Wang Q (2011) Simultaneous quantification of flavonoids and phenolic acids in Herba Scutellariae barbatae and its confused plants by high performance liquid chromatography tandem mass spectrometry. Food Chem 129(3):1297-1304

Russo M, Moccia S, Spagnuolo C, Tedesco I, Russo GL (2020) Roles of flavonoids against coronavirus infection. Chem-Biol Interact 328:109211

Sani TH, Hadjmohammadi M, Fatemi MH (2020) Extraction and determination of flavonoids in fruit juices and vegetables using $\mathrm{Fe}_{3} \mathrm{O}_{4} / \mathrm{SiO}_{2}$ magnetic nanoparticles modified with mixed hemi/admicelle cetyltrimethylammonium bromide and high performance liquid chromatography. J Seperation Sci 43:1224-1231

Scalbert A, Manach C, Morand C, Rémésy C, Jiménez L (2005) Dietary polyphenols and the prevention of diseases. Crit Rev Food Sci Nutr 45:287-306

Wang Z, Sun R, Wang Y, Li N, Lei L, Yang X, ..., Zhang H (2014) Determination of phenolic acids and flavonoids in raw propolis by silica-supported ionic liquid-based matrix solid phase dispersion extraction high performance liquid chromatography-diode array detection. J Chromatogr B 969: 205-212

Yang D, Li X, Meng D, Wang M, Yang Y (2017) Supramolecular solvents combined with layered double hydroxide-coated magnetic nanoparticles for extraction of bisphenols and 4-tert-octylphenol from fruit juices. Food Chem 237:870-876

Yilmaz E, Soylak M (2014) Development a novel supramolecular solvent microextraction procedure for copper in environmental samples and its determination by microsampling flame atomic absorption spectrometry. Talanta 126:191-195

Yola ML, Gupta VK, Eren T, Şen AE, Atar N (2014) A novel electro analytical nanosensor based on graphene oxide/silver nanoparticles for simultaneous determination of quercetin and morin. Electrochim Acta 120:204-211

Ziyatdinova G, Ziganshina E, Budnikov H (2014) Electrooxidation of morin on glassy carbon electrode modified by carboxylated singlewalled carbon nanotubes and surfactants. Electrochim Acta 145:209-216

Zohrabi P, Shamsipur M, Hashemi M, Hashemi B (2016) Liquid-phase microextraction of organophosphorus pesticides using supramolecular solvent as a carrier for ferrofluid. Talanta 160:340-346

Publisher's Note Springer Nature remains neutral with regard to jurisdictional claims in published maps and institutional affiliations. 